\title{
Separation of Urinary Catecholamines and Catecholamine Metabolites by High-Pressure Liquid Chromatography
}

\author{
Robert D. Hoeldtke ${ }^{1}$ and Philip L. Stetson \\ Department of Internal Medicine, Division of Endocrinology and Metabolism, Upjohn Center for \\ Clinical Pharmacology, The University of Michigan, Ann Arbor, Michigan 48109
}

Received November 14, 1979

\begin{abstract}
A series of high-pressure liquid chromatographic (hplc) procedures are described for the separation of all major and most minor catecholamine metabolites present in human urine. The amines and metabolites are first concentrated and partially purified by traditional methods, ion-exchange and alumina chromatography. Final separations are then performed with hplc. Our system is specifically designed to study dopamine $\beta$-hydroxylation in vivo. $\left[{ }^{3} \mathrm{H}\right]$ Dopamine is administered intravenously to human subjects, and then all the excreted $\left[{ }^{3} \mathrm{H}\right]$ dopamine metabolites and $\left[{ }^{3} \mathrm{H}\right]$ norepinephrine metabolites are separated and assayed. The high degree of resolution achieved with hplc makes it possible to separate the small population of $\left[{ }^{3} \mathrm{H}\right]$ norepinephrine metabolites from the much larger population of $\left[{ }^{3} \mathrm{H}\right]$ dopamine metabolites. The ratio of total excreted $\left[{ }^{3} \mathrm{H}\right]$ norepinephrine metabolites/total excreted $\left[{ }^{3} \mathrm{H}\right]$ dopamine metabolites averages $0.029 \pm 0.005$ in urine samples collected during the first $6 \mathrm{~h}$ following the administration of isotope.
\end{abstract}

Dopamine $\beta$-hydroxylase (EC 1.14.17.1; 3,4-dihydroxyphenylethylamine, ascorbate: oxygen oxidoreductase) $(\mathrm{DBH})^{2}$ catalyzes the last step in NE biosynthesis (1) and is found mainly in catecholamine-containing tissues, such as sympathetic neurons, brain, and adrenal medulla $(2,3)$. In noradrenergic neurons DBH is concentrated along with NE in the dense core vesicle of the nerve terminal and then released simultaneously with the neurotransmitter by a process of exo-

${ }^{1}$ To whom correspondence should be sent: Temple University Hospital, General Clinical Research Center, 3401 N. Broad St., Philadelphia, Pa. 19140.

${ }^{2}$ Abbreviations used: hplc, high-pressure liquid chromatography; THO, tritiated water; $\mathrm{DBH}$, dopamine $\beta$-hydroxylase; NE, norepinephrine; NMN, normetanephrine; EPI, epinephrine; DA, dopamine; MN, metanephrine; MTA, methoxytyramine; DHPG, dihydroxyphenylglycol; DHPE, dihydroxyphenylethanol; DHMA, dihydroxymandelic acid; DOPAC, dihydroxyphenylacetic acid; MHPG, 3-methoxy-4-hydroxyphenylglycol; MHPE, 3-methoxy-4-hydroxyphenylethanol; VMA, 3-methoxy-4-hydroxymandelic acid; HVA, 3-methoxy-4-hydroxyphenylacetic acid. cytosis (4). The limited tissue distribution of DBH has important implications for quantitative studies of dopamine $\beta$-hydroxylation in vivo. Since systemically given catecholamines are not well taken up into the brain (5), any dopamine $\beta$-hydroxylation which occurs following $\left[{ }^{3} \mathrm{H}\right] \mathrm{DA}$ administration to the whole patient must derive from that small fraction of the $\left[{ }^{3} \mathrm{H}\right] \mathrm{DA}$ which gains access to sympathetic neurons and adrenal medulla. Accordingly, a relatively low rate of dopamine $\beta$-hydroxylation would be anticipated following the administration of this substrate to whole animals or humans. Presumably for this reason, some studies of dopamine metabolism in rats, guinea pigs, and dogs $(6,7)$ have ignored the small pool of dopamine molecules which undergo $\beta$-hydroxylation.

Quantitation of the rate of dopamine $\beta$-hydroxylation in vivo has been a technically difficult problem in the past because of difficulties encountered in measuring the small 


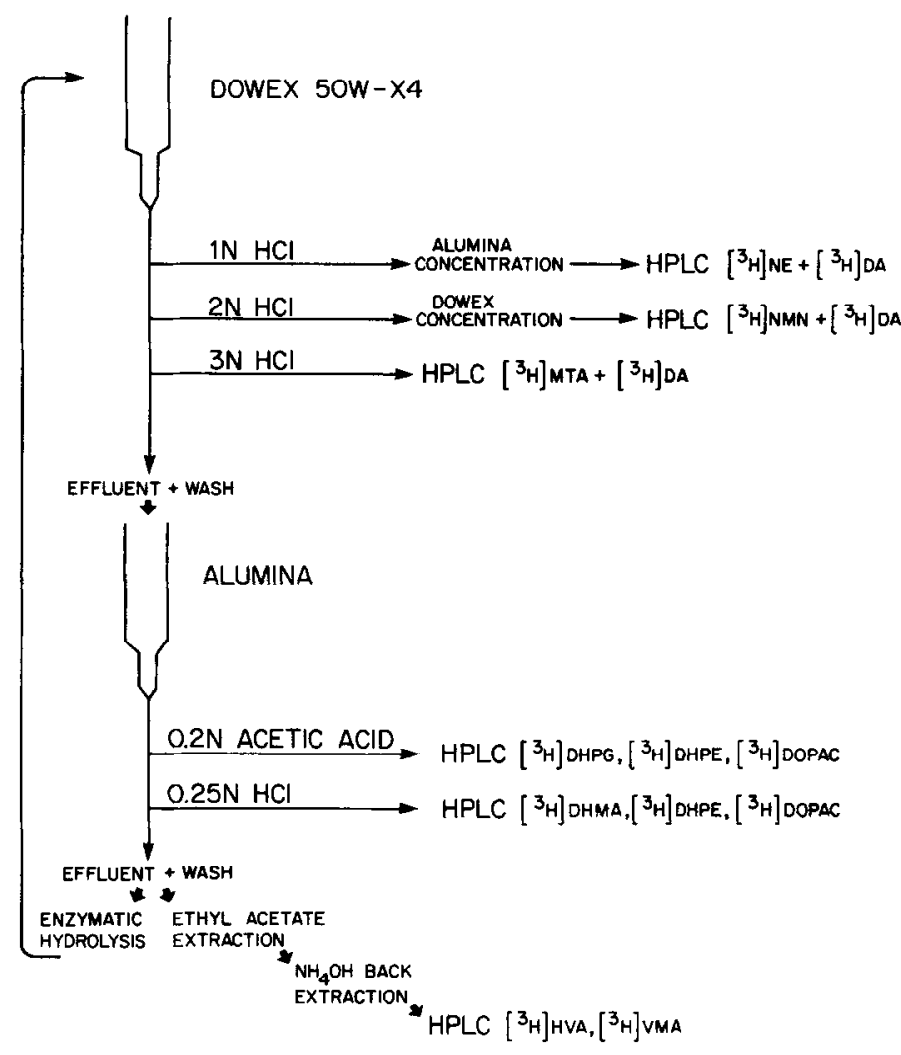

FIG. 1. Flow sheet for the separation of catecholamines and catecholamine metabolites. After the urine samples. had been passed over Dowex $50 \mathrm{~W}-\mathrm{X} 4$ and alumina, $50-\mathrm{ml}$ aliquots were subjected to enzymatic hydrolysis and then recycled through Dowex $50 \mathrm{~W}-\mathrm{X} 4$ and alumina for the assay of the conjugated deaminated catechols (DHPG, DHPE, DHMA, and DOPAC) and the total $O$-methylated deaminated metabolites (MHPG, MHPE, VMA, and HVA). Conjugated amines (NE, NMN, DA, and MTA) were assayed in separate aliquots of urine that were subjected to acid hydrolysis prior to Dowex 50W-X4 adsorption and elution was performed just as outlined for the free amines.

pool of NE metabolites in the presence of the much larger pool of excreted DA metabolites. With the recent development of hplc, however $(8-10)$, it is now possible to separate these two major families of catecholamine metabolites with relative ease. This is because the presence of a hydroxyl group on the $\beta$-position of these molecules significantly increases polarity and dramatically decreases hplc retention times. In this report, we describe a chromatographic system which combines hplc with standard techniques (ion-exchange and alumina chromatography) and effectively separates all major and most minor catecholamine metabolites (Fig. 1). Using these methods, we have investigated dopamine $\beta$-hydroxylation in man by quantitating the total pools of $\left[{ }^{3} \mathrm{H}\right] \mathrm{DA}$ and $\left[{ }^{3} \mathrm{H}\right] \mathrm{NE}$ metabolites excreted during the first $6 \mathrm{~h}$ after the intravenous administration of $\left[{ }^{3} \mathrm{H}\right] \mathrm{DA}$.

\section{MATERIALS AND METHODS}

Chemicals and equipment. All the catecholamines and catecholamine metabolites were purchased from Sigma except for MHPE which was purchased from Aldrich 
and DHPE which was purchased from Regis. Dopamine with a tritium label in the $\beta$-position of the side chain (sp act $13.3 \mathrm{Ci} / \mathrm{mmol}$ ) was obtained from New England Nuclear (NET-131). ${ }^{3}$ Dowex 50W-X4 (hydrogen form, 200-400 mesh) was purchased from BioRad Laboratories. Alumina was purchased from Chemical Manufacturing Corporation, Carle Place, New York. Glusulase (containing 14,995 units of sulfatase/ml and 163,604 units of glucuronidase $/ \mathrm{ml}$ ) was purchased from Endo Laboratories. High-pressure liquid chromatographic studies were performed with a single piston Altech pump, Model $110 \mathrm{~A}$. A reversed-phase $\mu$ Bondapak $\mathrm{C} 18$ column (3.9-mm i.d., 30-mm length) was purchased from Waters Associates.

Experimental protocol. We included four men and three women, age range 35 through 55 , in this study. Most of the seven subjects who participated were in good health, though one had fasting hyperglycemia (blood sugar $=120$ ) and a history of alcoholic hepatitis but normal liver function at the time of this experiment. Another patient had mild chronic obstructive pulmonary disease. A third patient was on insulin therapy for uncomplicated diabetes. The $\left[{ }^{3} \mathrm{H}\right] \mathrm{DA}$ infusions $(500 \mu \mathrm{Ci} / 70 \mathrm{~kg})$ were performed at the Clinical Research Unit of the University of Michigan Hospital after informed consent had been obtained. The $\left[{ }^{3} \mathrm{H}\right] \mathrm{DA}$ was passed through a $0.2-\mu \mathrm{m}$ Millipore filter and then administered intravenously at 9:00 AM over a 2 -min period. Urine was collected for the first $6 \mathrm{~h}$ after isotope administration in bottles containing $5 \mathrm{ml}$ of $6 \mathrm{~N} \mathrm{HCl}$. The sub-

\footnotetext{
${ }^{3}$ This enzyme substrate is actually a mixture of two distinct enantiomers, $(S)-\left[\beta^{-3} \mathrm{H}\right] \mathrm{DA}$ whose hydroxylation leads to the formation of $\left[{ }^{3} \mathrm{H}\right] \mathrm{NE}$ and $(R)-\left[\beta-{ }^{3} \mathrm{H}\right] \mathrm{DA}$ whose hydroxylation leads to the formation of THO. In rats the rate at which $\mathrm{THO}$ is released from this substrate in vivo can be used as an index of dopamine $\beta$-hydroxylation in the whole animal (11). We, thus, chose $\beta$-labeled DA for the present studies since we hope in the future to see whether the tritium release principle developed in rats can be employed as an in vivo assay of the human enzyme as well.
}

jects remained upright and ambulatory during the urine collection period, though they were allowed to sit down for lunch and a 5-min rest period each hour was allowed for those who needed it. The patients ingested a regular diet. Cigarette smoking was not allowed.

Separation of ${ }^{3} \mathrm{H}$-catecholamines and ${ }^{3} \mathrm{H}$-O-methylated amines. The labeled amines were extracted from the urine with Dowex $50 \mathrm{~W}-\mathrm{X} 4$ in the hydrogen form. Ascorbic acid $(0.2 \mathrm{ml}$ of $2 \%$ solution) and disodium EDT A ( $1.0 \mathrm{ml}$ of a $2 \%$ solution) were added to $48-\mathrm{ml}$ aliquots of urine immediately prior to their analysis. The urine was adjusted to $\mathrm{pH} 6.5$ and filtered through Whatman No. 1 paper and the loss of volume was recorded. The sample was then divided into two equal portions each of which was then passed over a $0.7 \times 4.5-\mathrm{cm}$ Dowex 50W-X4 column. Partial fractionation of the amines was achieved by eluting the columns with increasing concentrations of $\mathrm{HCl}$ according to the method of Taylor and Laverty (12).

The $1 \mathrm{~N} \mathrm{HCl}$ fractions from the duplicate Dowex columns were pooled (total volume $20 \mathrm{ml}$ ) and the $\left[{ }^{3} \mathrm{H}\right] \mathrm{NE}$ was concentrated by passing this eluate over a $0.7 \times 1.5-\mathrm{cm}$ alumina column. The ${ }^{3} \mathrm{H}$-catecholamines were eluted with $0.2 \mathrm{~N}$ acetic acid (final volume $3.5 \mathrm{ml}$ ). The $\left[{ }^{3} \mathrm{H}\right] \mathrm{NE}$ was then separated from the $\left[\beta-{ }^{3} \mathrm{H}\right] \mathrm{DA}$ by hplc.

The $2 \mathrm{~N} \mathrm{HCl}$ fractions from the duplicate Dowex columns were also pooled (total volumes $25 \mathrm{ml}$ ) and the [ $\left.{ }^{3} \mathrm{H}\right] \mathrm{NMN}$ was concentrated by passing this eluate over a second Dowex column. The $1 \mathrm{~N} \mathrm{HCl}$ fraction of the second column was discarded, and then $\left[{ }^{3} \mathrm{H}\right]$ NMN and $\left[\beta^{3} \mathrm{H}\right] \mathrm{DA}$ were eluted with 6.5 $\mathrm{ml}$ of $4 \mathrm{~N} \mathrm{HCl}$. The ${ }^{3} \mathrm{H}$-amines in this fraction were then separated by hplc.

The conjugated amines were assayed in separate aliquots of urine from which the free ${ }^{3} \mathrm{H}$-catecholamines were first removed by passage over alumina. The alumina filtrates were then subjected to acid hydrolysis under the conditions previously described 
(13). The conjugated ${ }^{3} \mathrm{H}$-catecholamines (now present as free compounds) were then extracted by the Dowex 50W-X4 columns as described above for the unhydrolyzed samples. The rate of excretion of the ${ }^{3} \mathrm{H}$ conjugated $O$-methylated amines could be calculated by subtracting the rate of excretion of the free compounds (as measured in the unhydrolyzed samples) from the rate of excretion in the free and conjugated $O$-methylated amines (as measured in the hydrolyzed samples).

Reversed-phase hplc of the amine fractions was performed after equilibration of the columns with potassium monophosphate buffer $(0.05 \mathrm{~m})$ containing $5 \%$ methanol and $60 \mathrm{mg} /$ liter of sodium octyl sulfonate as a paired ion reagent (9). Mobile-phase flow rate was $0.8 \mathrm{ml} / \mathrm{min}$, and $100-\mu l$ aliquots were used for all analyses. Retention times were determined by adding standard amines $(0.10-0.30 \mathrm{mg} / \mathrm{ml})$ to the samples, and monitoring ultraviolet absorbance at $254 \mathrm{~nm}$. We simultaneously collected 30-s fractions, and assayed the ${ }^{3} \mathrm{H}$-amines by liquid scintillation spectrophotometry (Beckman LS-250). With older columns retention times could be improved by using trichloroacetic acid $\mathbf{0} 0.04$ M) as the paired ion reagent as suggested by Freed and Asmus (10).

Separation of deaminated catechols. The neutral and acidic catechol metabolites (DHPG, DHPE, DHMA, and DOPAC) were extracted from pooled effuents of the Dowex $50 \mathrm{~W}-\mathrm{X} 4$ columns (total volume $60 \mathrm{ml}$ ) by absorption at $\mathrm{pH} 8.6$ onto alumina columns $(0.7 \times 3.0 \mathrm{~cm})$. After an $8-\mathrm{ml}_{2} \mathrm{O}$ wash, the neutral catechols (DHPG and DHPE) were eluted with $5.5 \mathrm{ml}$ of $0.2 \mathrm{~N}$ acetic acid, and then the acidic catechols (DHMA and DOPAC) were eluted with $5.5 \mathrm{ml}$ of 0.25 $\mathrm{N} \mathrm{HCl}$ (14).

The 0.2 acetic acid fraction was subjected to reversed-phase hplc following preequilibration with $0.025 \mathrm{M}$ potassium monophosphate buffer, $\mathrm{pH} 4.75$, containing citric acid $(0.01 \mathrm{M})$ and $6 \%$ methanol. Sodium heptyl sulfonate $(60 \mathrm{mg} /$ liter $)$ was used as the paired ion reagent. After the DHPG had eluted, the buffer was made $16 \%$ with respect to methanol. Flow rate of the mobile phase was $0.8 \mathrm{ml} / \mathrm{min}$. Retention times were determined by adding standard compounds and then simultaneously monitoring optical density and collecting fractions for radioactivity determination as described for the amines.

The $0.25 \mathrm{~N} \mathrm{HCl}$ fraction was subjected to hplc in $0.01 \mathrm{M} \mathrm{H}_{3} \mathrm{PO}_{4}$ containing $20 \mathrm{mg}$ of tetraheptylammonium chloride as a paired ion reagent. The flow rate of the mobile phase was $0.6 \mathrm{ml} / \mathrm{min}$. After the DHMA had eluted, we made the mobile phase $20 \%$ with respect to methanol (to hasten the elution of the DA metabolites).

Separation of $O$-methylated deaminated metabolites. Urine which had been passed over Dowex 50W-X4 (which removed the ${ }^{3} \mathrm{H}$-amines) and alumina (which removed ${ }^{3} \mathrm{H}$ catechols) was used for the assay of neutral and acidic $O$-methylated metabolites (VMA, HVA, MHPG, MHPE). Aliquots of the alumina effluents $(23 \mathrm{ml})$ were adjusted to pH 1.0 with $6 \mathrm{~N} \mathrm{HCl}$, and then the sample was transferred to a 50-ml glass-stoppered centrifuge tube, saturated with solid $\mathrm{NaCl}$, and an equal volume of ethyl acetate was added. After mechanical shaking for $10 \mathrm{~min}$, the samples were centrifuged $(5000 \mathrm{~g}, 10$ $\mathrm{min}$ ) and the organic phase was transferred to a second set of tubes. The process was repeated with a second portion of ethyl acetate, and the organic phases from the two extractions were combined. Back extraction was performed by mechanically shaking the pooled organic phases for 10 min with $4 \mathrm{ml}$ of $2.5 \mathrm{~N} \mathrm{NH}_{4} \mathrm{OH}$. The organic phase was discarded, and most of the $\mathrm{NH}_{3}$ was removed from the aqueous phase by allowing it to stand $24 \mathrm{~h}$ under a hood at room temperature. The sample was then adjusted to $\mathrm{pH}$ 4.5 with $1 \mathrm{~N} \mathrm{HCl}$ and the alteration in volume recorded. Aliquots $(100 \mu \mathrm{l})$ of these samples were analyzed by a hplc system 
utilizing $0.025 \mathrm{M}$ potassium monophosphate buffer containing $0.01 \mathrm{M}$ citric acid and 60 mg sodium heptylsulfonate per liter. The buffer was adjusted to $\mathrm{pH} 4.0$ with $1 \mathrm{~N} \mathrm{NaOH}$. The initial methanol concentration was $12 \%$; this was stepped up to $25 \%$ after the VMA and MHPG had eluted.

Enzymatic hydrolysis and the assay of conjugated metabolites. The remaining alumina effluent (that not used for the assay of free deaminated, $O$-methylated metabolites) was subjected to enzymatic hydrolysis with glusulase according to the method of Bigelow et al. (15). Following precipitation of the phosphates and sulfates, the barium was removed by addition of saturated potassium carbonate as described by Shimizu and LaBrosse (16). Following the enzymatic hydrolysis and precipitation of proteins (15), the samples were recycled through Dowex $50 \mathrm{~W}-\mathrm{X} 4$ and alumina, just as described for the unhydrolyzed samples (see Fig. 1). We did not, however, clutc the ${ }^{3} \mathrm{H}$-amines liberated in the enzymatic hydrolysis from the Dowex columns since these metabolites were assayed in separate aliquots of urine treated with acid hydrolysis as described above. ${ }^{4}$ The neutral and acidic deaminated ${ }^{3} \mathrm{H}$-catechols, excreted as conjugates but now present as free compounds, were determined in their respective alumina eluate fractions. Aliquots of the final alumina effluent were used for the assay of total $\left[{ }^{3} \mathrm{H}\right] \mathrm{VMA},\left[{ }^{3} \mathrm{H}\right]-$ HVA, $\left[{ }^{3} \mathrm{H}\right] \mathrm{MHPG}$, and $\left[{ }^{3} \mathrm{H}\right] \mathrm{MHPE}$ as described above for the unhydrolyzed samples.

All data are corrected for losses associated with the gravity chromatography. Recoveries were determined by measuring the $\mathrm{OD}_{254}$ of standards carried through the above separation techniques. The recovery of all the compounds studied ranged between 50 and $80 \%$, except for NMN whose recovery

\footnotetext{
+ We needed to employ both acid hydrolysis and enzymatic hydrolysis since the recovery of catecholamine is higher after acid hydrolysis than after the enzymatic treatment, whereas the reverse is true for MHPG $(13,15)$.
}

through the two Dowex columns averaged only $40 \%$. No correlation was made for losses associated with the hplc. We assumed the enzymatic hydrolysis was $85 \%$ effective (16) and the acid hydrolysis was $100 \%$ effective.

\section{RESULTS}

\section{Separation of ${ }^{3} \mathrm{H}$ Catecholamines and ${ }^{3} \mathrm{H}-\mathrm{O}$-Methylated Amines}

The catecholamines and their $O$-methylated derivatives could be readily separated by a single hplc system using potassium monophosphate buffer $(0.05 \mathrm{M})$ containing $5 \%$ methanol and sodium octylsulfonate $(60$ $\mathrm{mg} / \mathrm{liter}$ ) as a paired ion reagent (9) (Fig. 2). When $100-\mu$ l aliquots of the various acidic Dowex eluates were subjected directly to hplc, however, the radioactivity eluting in $\left[{ }^{3} \mathrm{H}\right] \mathrm{NE}$ and $\left[{ }^{3} \mathrm{H}\right] \mathrm{NMN}$ fractions was barely distinguishable from background for some of our samples. For this reason, we concentrated the $\left[{ }^{3} \mathrm{H}\right] \mathrm{NE}$ in the $1 \mathrm{~N} \mathrm{HCl}$ fractions from two Dowex columns with a single alumina column, and the $\left[{ }^{3} \mathrm{H}\right] \mathrm{NMN}$ in the $2 \mathrm{~N}$ $\mathrm{HCl}$ fractions of duplicate Dowex columns with another Dowex column. Using this protocol, we were able to detect free and conjugated $\left[{ }^{3} \mathrm{H}\right] \mathrm{NE}$ in all of the samples analyzed. Only small amounts of radioactivity (see Table 1) eluted in free $\left[{ }^{3} \mathrm{H}\right] \mathrm{NMN}$ fractions, even after the concentration step, and in some samples free $\left[{ }^{3} \mathrm{H}\right] \mathrm{NMN}$ was barely detectable. Following acid hydrolysis of the urine, however, a $\left[{ }^{3} \mathrm{H}\right] \mathrm{NMN}$ peak could be readily distinguished in all of our samples (Fig. 2). Negligible amounts of radioactivity eluted in those fractions that would have contained $\left[{ }^{3} \mathrm{H}\right] \mathrm{EPI}$ and $\left[{ }^{3} \mathrm{H}\right] \mathrm{MN}$.

\section{Separation of Deaminated Catechols}

A mixture of standard neutral and acidic catechol metabolites (DHPG, DHPE, DHMA, and DOPAC) could be separated by a single hplc system (Fig. 3) using $0.025 \mathrm{M}$ 


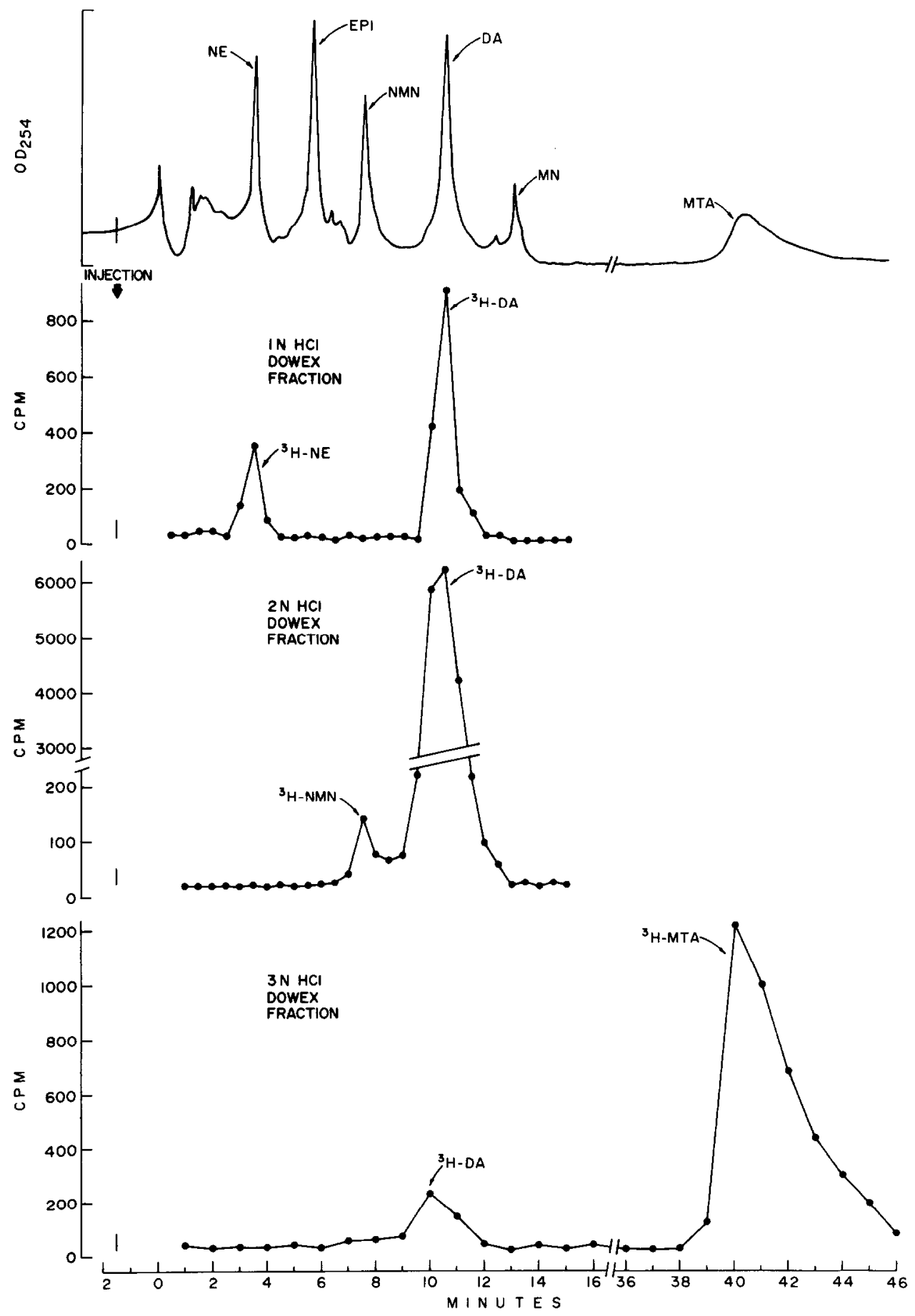

Fig. 2. High-pressure liquid chromatographic separation of ${ }^{3} \mathrm{H}$-catecholamine and ${ }^{3} \mathrm{H}-\mathrm{O}$-methylated amines. The $1 \mathrm{~N} \mathrm{HCl}$ eluates from two Dowex $50 \mathrm{~W}-\mathrm{X} 4$ columns were pooled, and the ${ }^{3} \mathrm{H} \mid \mathrm{NE}$ was concentrated by passing the resulting sample over alumina at $\mathrm{pH} 8.6$ and eluting the ${ }^{3} \mathrm{H}$-amines in a small volume $(3.5 \mathrm{ml})$ of $0.2 \mathrm{~N}$ acetic acid. A mixture of authentic amines were added to the resulting 
TABLE 1

Distribution of BH-Catecholamine DeRIVATIVES AMONG THE $\left[{ }^{3} \mathrm{H}\right] \mathrm{DA}$ AND $\left[{ }^{3} \mathrm{H}\right]$ NE Metabolite Pools ${ }^{\alpha}$

\begin{tabular}{|c|c|c|}
\hline $\begin{array}{c}\text { Total radioac } \\
\text { excreted } / 6\end{array}$ & ivity & $57.0 \pm 6.4$ \\
\hline \multicolumn{3}{|c|}{${ }^{3} \mathrm{H}[\mathrm{NE}]$ metabolites } \\
\hline \multirow[t]{2}{*}[{}^{3}\mathrm{H}]{$\mathrm{NE}$} & free & $0.0695 \pm 0.0149$ \\
\hline & conjugated & $0.0334 \pm 0.0079$ \\
\hline \multirow[t]{2}{*}[{}^{3}\mathrm{H}]{$\mathrm{NMN}$} & free & $0.0138 \pm 0.0039$ \\
\hline & conjugated & $0.0297 \pm 0.0103$ \\
\hline \multirow[t]{2}{*}[{}^{3}\mathrm{H}]{$\mathrm{DHPG}$} & free & $0.0313 \pm 0.0110$ \\
\hline & conjugated & $0.0467 \pm 0.0142$ \\
\hline \multirow[t]{2}{*}[{}^{3}\mathrm{H}]{$\mathrm{DHM} A$} & free & $0.0371 \pm 0.0010$ \\
\hline & conjugated & $0.0066 \pm 0.0040$ \\
\hline$\left[{ }^{3} \mathrm{H}\right]$ VMA & free & $0.790 \pm 0.111$ \\
\hline$\left[{ }^{3} \mathrm{H}\right] \mathrm{MHPG}$ & total & $0.213 \pm 0.033$ \\
\hline $\begin{array}{r}\text { Total }\left[{ }^{3} \mathbf{H}\right] \\
\text { metabolit }\end{array}$ & Total $\left[{ }^{3} \mathrm{H}\right] \mathrm{NE}$ & $1.28 \pm 0.16$ \\
\hline \multicolumn{3}{|l|}{${ }^{3} \mathrm{H}[\mathrm{DA}]$ metabolites } \\
\hline \multirow[t]{2}{*}[\beta-^{3}\mathrm{H}]{$\mathrm{DA}$} & free & $6.54 \pm 0.97$ \\
\hline & conjugated & $5.41 \pm 1.14$ \\
\hline \multirow[t]{2}{*}[{}^{3}\mathrm{H}]{$\mathrm{MTA}$} & free & $1.32 \pm 0.20$ \\
\hline & conjugated & $3.33 \pm 0.83$ \\
\hline \multicolumn{2}{|c|}{$\left[{ }^{3} \mathrm{H}\right]$ DOPAC free } & $3.53 \pm 0.55$ \\
\hline & conjugated & $2.51 \pm 0.55$ \\
\hline \multirow[t]{2}{*}[{}^{3}\mathrm{H}]{$\mathrm{DHPE}$} & free & $0.022 \pm 0.005$ \\
\hline & conjugated & $0.111 \pm 0.024$ \\
\hline$\left[{ }^{3} \mathrm{H}\right] \mathrm{HVA}$ & free & $22.61 \pm 2.80$ \\
\hline$\left[{ }^{3} \mathrm{H}\right] \mathrm{MHPE}$ & total & Trace \\
\hline \multicolumn{3}{|c|}{ Total $\left[{ }^{3} \mathrm{H}\right] \mathrm{DA}$} \\
\hline metabolit & e pool & $45.4 \pm 3.7$ \\
\hline
\end{tabular}

${ }^{a}$ All numbers represent the mean $\% \pm \mathrm{SE}$ of the administered radioactivity excreted in the various ${ }^{3} \mathrm{H}$ catecholamine metabolite pools. The data were obtained from seven control subjects on urine collected for the first $6 \mathrm{~h}$ after the intravenous administration of $\left[{ }^{3} \mathrm{H}\right] \mathrm{DA}(500 \mu \mathrm{C} / 70 \mathrm{~kg})$ given gradually over $2 \mathrm{~min}$.

potassium monophosphate buffer containing citric acid $(0.01 \mathrm{M})$ and an initial methanol concentration of $6 \%$ and a final methanol concentration of $16 \%$. When the alumina columns were eluted directly with $0.25 \mathrm{~N}$ $\mathrm{HCl}$ (i.e., omitting the $0.2 \mathrm{~N}$ acetic acid wash), an unidentified early eluting peak of radioactivity obscured the $\left[{ }^{3} \mathrm{H}\right] \mathrm{DHMA}$ peak. High-pressure liquid chromatography systems that separated this unidentified peak from [ $\left.{ }^{3} \mathrm{H}\right] \mathrm{DHMA}$ compromised the separation of $\left[{ }^{3} \mathrm{H}\right] \mathrm{DHMA}$ from $\left[{ }^{3} \mathrm{H}\right] \mathrm{DHPG}$. For this reason, we separated the $\left[{ }^{3} \mathrm{H}\right] \mathrm{DHPG}$ from the $\left[{ }^{3} \mathrm{H}\right]$ DHMA by fractional elution of the alumina columns by increasingly strong acids; $\left[{ }^{3} \mathrm{H}\right] \mathrm{DHPG}$ eluted in the $0.2 \mathrm{~N}$ acetic acid fraction and $\left[{ }^{3} \mathrm{H}\right] \mathrm{DHMA}$ eluted in the $0.25 \mathrm{~N} \mathrm{HCl}$ fraction (14). The $0.2 \mathrm{~N}$ acetic acid fraction was then analyzed by the neutral hplc system described above, and the $0.25 \mathrm{~N} \mathrm{HCl}$ fraction was analyzed by an acidic hplc system $\left(0.01 \mathrm{M} \mathrm{H}_{3} \mathrm{PO}_{4}\right.$ containing $20 \mathrm{mg}$ of tetraheptylammonium chloride/ liter) which retained the $\left[{ }^{3} \mathrm{H}\right] \mathrm{DHMA}$ sufficiently to separate it from the interfering peak which eluted earlier (Fig. 4). Though this acidic system did not separate $\left[{ }^{3} \mathrm{H}\right]$ DHPG from $\left[{ }^{3} \mathrm{H}\right] \mathrm{DHMA}$ this was of no importance since the former eluted in the $0.2 \mathrm{~N}$ acetic acid fraction and minimal cross contamination of the $0.25 \mathrm{~N} \mathrm{HCl}$ fraction occurred. Though the fractional elution of the alumina column effectively separated $\left[{ }^{3} \mathrm{H}\right]$ DHPG from $\left[{ }^{3} \mathrm{H}\right] \mathrm{DHMA}$ the corresponding $\left[{ }^{3} \mathrm{H}\right] \mathrm{DA}$ metabolites, $\left[{ }^{3} \mathrm{H}\right] \mathrm{DHPE}$ and $\left[{ }^{3} \mathrm{H}\right]-$ DOPAC, were not reliably separated by this protocol, so it was necessary to measure these labeled metabolites in the $0.2 \mathrm{~N}$ acetic acid fraction as well as the $0.25 \mathrm{~N} \mathrm{HCl}$ fraction (Fig. 1).

Using this protocol we were able to identify free $\left[{ }^{3} \mathrm{H}\right] \mathrm{DHPG}$ in five of seven samples;

sample, and hplc was performed. $\mathrm{OD}_{254}$ was monitored while fractions were collected for radioactivity determination. High-pressure liquid chromatography was performed with a mobile phase of $0.05 \mathrm{M}$ potassium monophosphate buffer containing $5 \%$ methanol and sodium octylsulfonate as a paired ion reagent. The $2 \mathrm{~N} \mathrm{HCl}$ Dowex $50 \mathrm{~W}$-X4 fractions from two columns were pooled and the ${ }^{3} \mathrm{H}$-amines concentrated by another Dowex $50 \mathrm{~W}-\mathrm{X} 4$ column. After washing this column with $5 \mathrm{ml}$ of $\mathrm{H}_{2} \mathrm{O}$ and $14 \mathrm{ml}$ of $1 \mathrm{~N} \mathrm{HCl} .\left[{ }^{3} \mathrm{H}\right] \mathrm{NMN}$ and $\left[\beta^{3} \mathrm{H}\right] \mathrm{DA}$ were eluted with $6.5 \mathrm{ml}$ of $4 \mathrm{~N} \mathrm{HCl}$. High-pressure liquid chromatography was then performed as described for the $1 \mathrm{~N} \mathrm{HCl}$ fractions. The $3 \mathrm{~N} \mathrm{HCl} \mathrm{Dowex}$ fractions were subjected directly to hplc. 


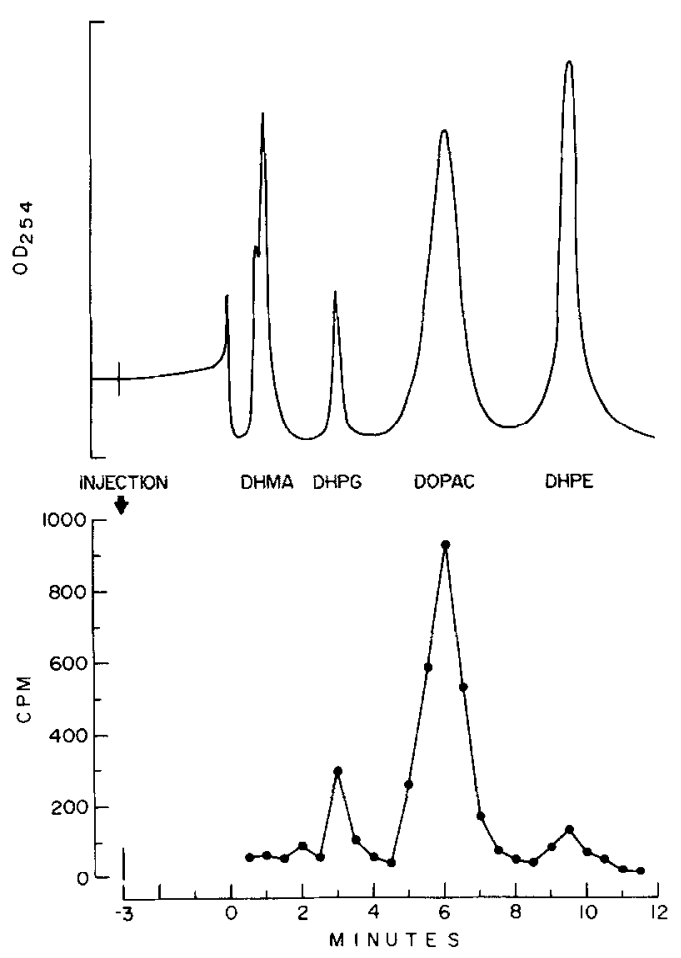

Fig. 3. Neutral hplc system for separation ${ }^{3} \mathrm{H}$-deaminated catechols. Aliquots $(100 \mu 1)$ of the $0.2 \mathrm{~N}$ acetic acid eluate of the alumina columns were subjected to hplc following preequilibration of the column with $0.025 \mathrm{M}$ potassium phosphate buffer, $\mathrm{pH} 4.75$, containing citric acid $(0.01 \mathrm{M})$ and $6 \%$ methanol. Sodium heptylsulfonate $(60 \mathrm{mg} / \mathrm{liter})$ was used as the paired ion reagent. Flow rate of the mobile phase was $0.8 \mathrm{ml} / \mathrm{min}$. After $\left[{ }^{3} \mathrm{H}\right]$ DHMA and $\left[{ }^{3} \mathrm{H}\right]$ DHPG had eluted the mobile phase was made $16 \%$ with respect to methanol.

following enzymatic hydrolysis of the alumina effiuent and recycling of the sample through Dowex and alumina, hplc analysis of the $0.2 \mathrm{~N}$ acetic acid eluate revealed that a peak of radioactivity eluting with authentic DHPG could be identified in all seven samples. ${ }^{5}$ Free $\left[{ }^{3} \mathrm{H}\right]$ DHMA was also identified in all of our samples, but following enzymatic hydrolysis radioactivity coeluted with standard DHMA in only three of seven samples.

5 Conjugated DHPG is a known metabolite of NE in rat brain $(17,18)$, and has recently been identified in human urine by a mass spectroscopic method (19).

\section{Separation of $\mathrm{O}$-Methylated Deaminated Metabolites}

The neutral and acidic $O$-methylated metabolites (VMA, HVA, MHPG, and MHPE) were separated by hplc using 0.025 $M$ potassium monophosphate buffer containing $0.01 \mathrm{M}$ citric acid and $60 \mathrm{mg}$ sodium

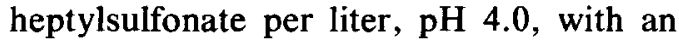
initial methanol concentration of $12 \%$ and a final methanol concentration of $25 \%$ (Fig. 5).
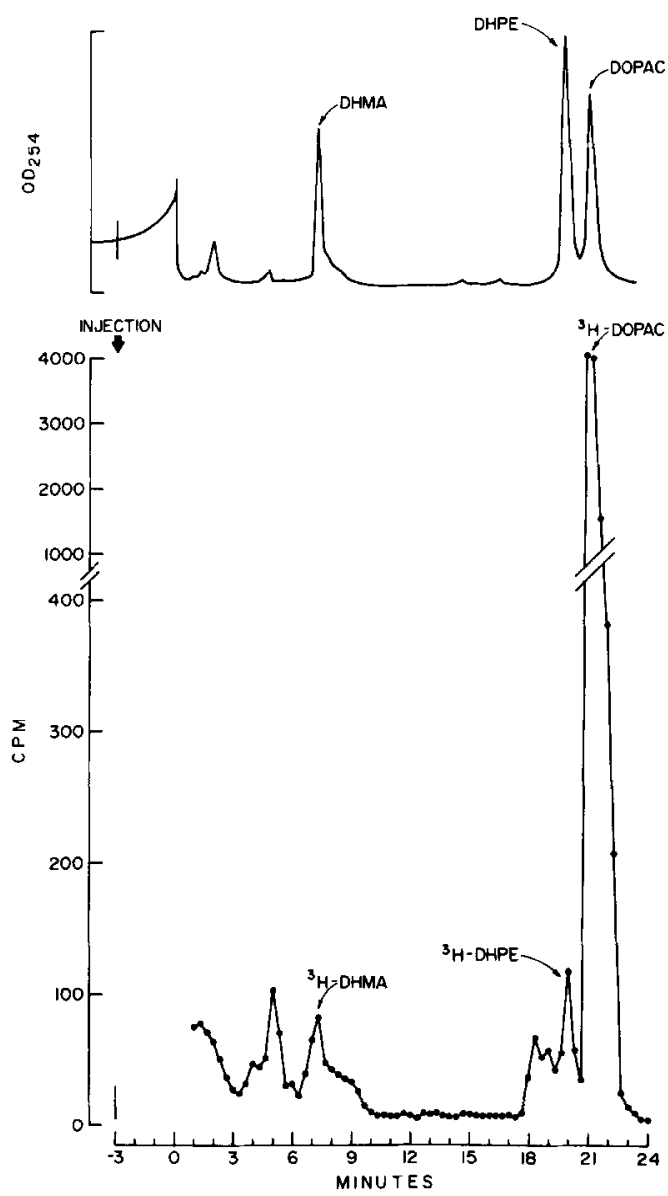

FIG. 4. Acidic hplc system for separation of ${ }^{3} \mathrm{H}$-deaminated catechol metabolites. Aliquots $(100 \mu \mathrm{l})$ of the $0.25 \mathrm{~N} \mathrm{HCl}$ alumina eluate were subjected to hplc following preequilibration of the column with $0.01 \mathrm{M}$ $\mathrm{H}_{3} \mathrm{PO}_{4}$ containing $20 \mathrm{mg} /$ liter of tetraheptylammonium chloride. After [ $\left.{ }^{3} \mathrm{H}\right] \mathrm{DHMA}$ had eluted, the mobile phase was made $20 \%$ with respect to methanol. The flow rate was $0.6 \mathrm{ml} / \mathrm{min}$. 

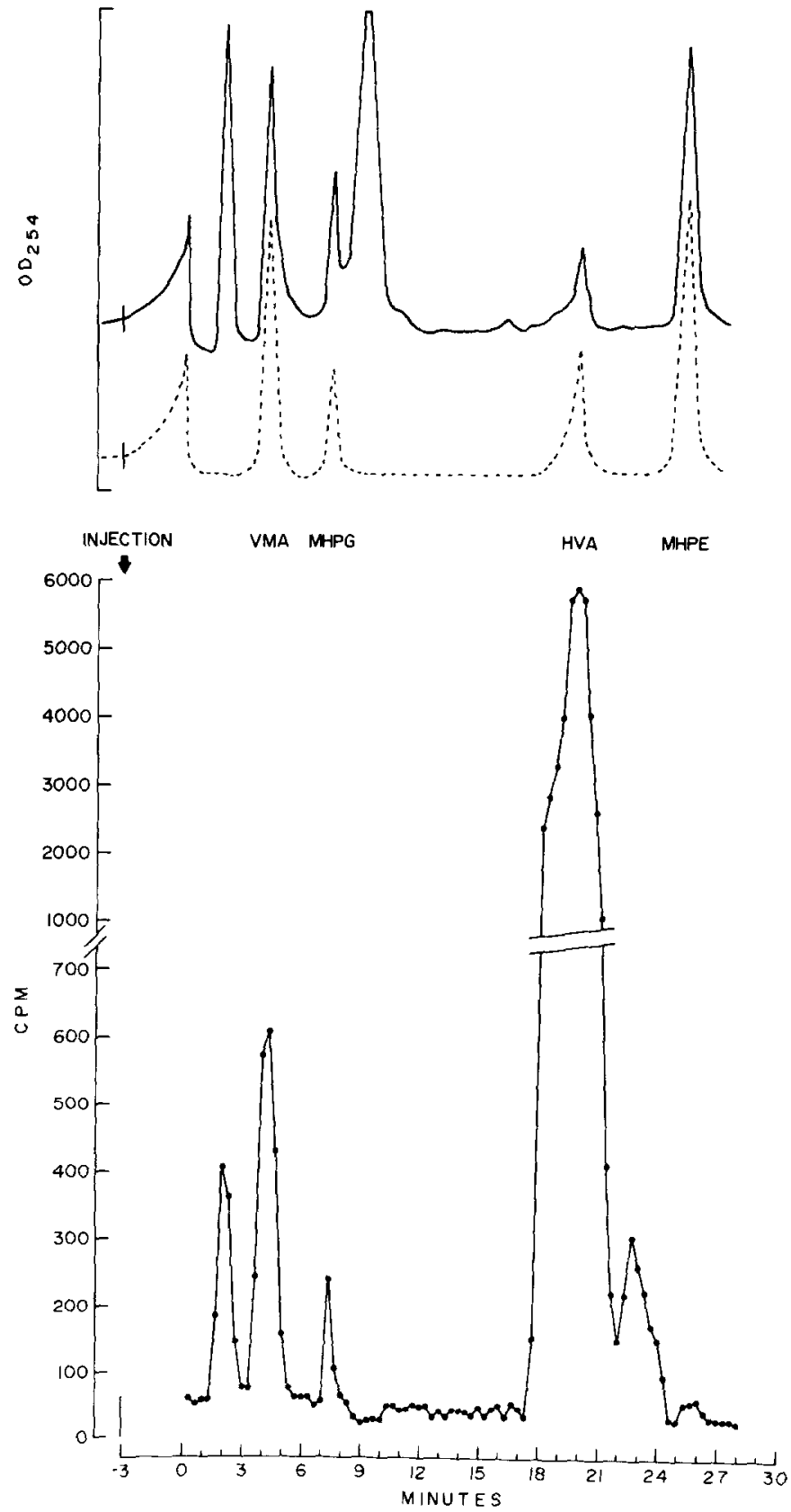

FIG. 5. High-pressure liquid chromatographic separation of the $O$-methylated deaminated metabolites. The $O$-methylated deaminated metabolites were extracted from the Dowex $5 \mathrm{~W}$-X4 and alumina effluents by extraction into ethyl acetate from an acidic $(\mathrm{pH} 1.0)$ salt saturated aqueous phases. Following back extraction with $2.5 \mathrm{~N} \mathrm{NH}_{4} \mathrm{OH}$ (see Methods), the resulting aqueous phase, following neutraliza-

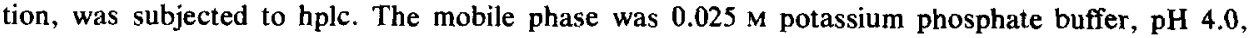
containing $0.01 \mathrm{M}$ citric acid and $60 \mathrm{mg}$ sodium heptylsulfonate per liter. The initial methanol concentration was $12 \%$; after the $l^{3} \mathrm{H} J \mathrm{VMA}$ and $\left[{ }^{3} \mathrm{H}\right] \mathrm{MHPG}$ had eluted, the mobile phase was made $25 \%$ with respect to methanol. 
We found a radioactivity peak eluting with standard MHPG only in samples subjected to enzymatic hydrolysis, whereas $\left[{ }^{3} \mathrm{H}\right] \mathrm{VMA}$ was identified in unhydrolyzed as well as hydrolyzed samples. We routinely assayed the $\left[{ }^{3} \mathrm{H}\right]$ VMA only in unhydrolyzed samples since incubation with glusulase did not increase the yield of this labeled metabolite. This finding is in disagreement with Goodall and Alton's report of a large (1.0\% of administered radioactivity), labeled peak identified as conjugated $\left[{ }^{3} \mathrm{H}\right]$ VMA (20). In most of our samples, the amount of radioactivity eluting in fractions that would have contained $\left[{ }^{3} \mathrm{H}\right] \mathrm{MHPE}$ was negligible. As anticipated from previous studies $(6,7,20)$ a large $\left[{ }^{3} \mathrm{H}\right] \mathrm{HVA}$ peak was present in all samples, this being by far the quantitatively most important $\left[\beta-{ }^{3} \mathrm{H}\right] \mathrm{DA}$ metabolite (Table 1).

\section{DISCUSSION}

There is little agreement in the existing literature on the rate at which systemically administered labeled dopamine undergoes $\beta$-hydroxylation in whole animals and human subjects. In a number of studies of dopamine metabolism, the pool of $\beta$-hydroxylated metabolites has apparently been too small to be resolved by the chromatographic procedure employed $(6,7)$. We estimated, however, in rats on the basis of a tritium release assay that the in vivo rate of dopamine $\beta$-hydroxylation was $3.4 \pm 0.3 \% / 10$ min (11). Similarly, following the intravenous administration of labeled tyramine to rats, there is rapid accumulation of the labeled $\beta$-hydroxylated derivative octopamine in sympathetically innervated organs, such as heart and spleen (21). Similarly, another phenylethylamine $\mathrm{DBH}$ substrate, hydroxyamphetamine, readily undergoes in vivo $\beta$-hydroxylation in man. Sjoerdsma and von Studnitz observed that following the oral administration of hydroxyamphetamine to humans, between 4 and $9 \%$ of the adminis- tered drug is converted over a $24-\mathrm{h}$ period to the $\beta$-hydroxylated product, hydroxynorephedrine (22).

The data in the present report do not agree well with a previous study of dopamine $\beta$-hydroxylation in man. Goodall and Alton reported that during the first $6 \mathrm{~h}$ following the administration of $\left[{ }^{14} \mathrm{C}\right] \mathrm{DA}$ to humans, $8 \%$ of the administered isotope could be accounted for as excreted metabolites of $\left[{ }^{14} \mathrm{C}\right]-$ NE (20). In the present study, however, we found that only $1.28 \pm 0.16 \%$ of the administered radioactivity was excreted in the $\left[{ }^{3} \mathrm{H}\right] \mathrm{NE}$ metabolite pool during the first $6 \mathrm{~h}$ following the administration of isotope (Table 1) and the ratio of total $\left[{ }^{3} \mathrm{H}\right] \mathrm{NE}$ metabolites/total $\left[{ }^{3} \mathrm{H}\right] \mathrm{DA}$ metabolites was 0.029 $\pm 0.005(\mathrm{SEM})$. These estimates of $\left[{ }^{3} \mathrm{H}\right] \mathrm{NE}$ metabolite excretion would be doubled if we had used a substrate whose label could not be released during the enzymatic hydroxylation. ${ }^{3}$ Even with this correction, however, our estimate of the rate of dopamine $\beta$-hydroxylation in vivo remains much lower than that reported by Goodall and Alton. Since higher degrees of resolution can be achieved with hplc than with traditional ion-exchange chromatography, our estimate of the $\left[{ }^{3} \mathrm{H}\right] \mathrm{NE}$ metabolite pool is probably more accurate than that based on the older methodology. We suspect, for example, that the large peak of radioactivity (1.0\% of administered isotope) identified as conjugated $\left[{ }^{3} \mathrm{H}\right]$ VMA represented some interfering compound since we were unable to even identify this metabolite in our chromatographic system. Alternatively, differences in experimental protocol may explain the discrepancy between our data and that reported by Goodall and Alton. We gave the dopamine over $2 \mathrm{~min}$ and these previous investigators administered it over $4 \mathrm{~h}$ as a constant infusion. Moreover, we used $\left[{ }^{3} \mathrm{H}\right]$ DA, whereas they used $\left[{ }^{4} \mathrm{C}\right] \mathrm{DA}$.

Since hplc retention time is dramatically altered by the polarity change caused by the presence of a hydroxyl group on the 
$\beta$-position of the catechol side chain, this technique is ideal for the separation of NE from DA metabolites. Yet our attempts to accurately quantitate the total $\left[{ }^{3} \mathrm{H}\right] \mathrm{NE}$ metabolite pool has been complicated by the presence of a number of unidentified peaks of radioactivity whose low hplc retention times suggest a high degree of polarity possibly indicative of a hydroxyl group on the $\beta$-position of the molecule. In particular, the basis of the chromatographic behavior (rapid hplc elution) of the peak of radioactivity eluting just before $\left[{ }^{3} \mathrm{H}\right]$ DHMA (See Fig. 4 ) and the peak of radioactivity eluting just before [ $\left.{ }^{3} \mathrm{H}\right]$ VMA (see Fig. 5), one would predict that these labeled metabolites are very polar compounds and, therefore, apt to be $\left[{ }^{3} \mathrm{H}\right] \mathrm{NE}$ (rather than $\left[{ }^{3} \mathrm{H}\right] \mathrm{DA}$ ) metabolites. The amount of radioactivity eluting in the unidentified peak prior to $\left.{ }^{3} \mathrm{H}\right] \mathrm{VMA}$ approaches that eluting which $\left[{ }^{3} \mathrm{H}\right] \mathrm{VMA}$ itself, and thus would appear (if derived from $\left.\left[{ }^{3} \mathrm{H}\right] \mathrm{NE}\right)$ to be a quantitatively important metabolite. Attempts to identify this labeled compound, which was observed equally in unhydrolyzed and hydrolyzed urine, are currently in progress.

\section{ACKNOWLEDGMENTS}

This work was supported in part by the Michigan Diabetes Research and Training Center Grant 5-P60AM20572, the NIH Multicategorical Clinical Research Center Grant 5-M01RR-42, and USPHS R01 AM00888 and T32 AM07245.

\section{REFERENCES}

1. Levin, E. Y., and Kaufman, S. (1961) J. Biol. Chem. 236, 2043-2049.
2. Geffen, L. B., and Livett, B. G. (1971) Physiol. Rev. 51, 98-157.

3. Axelrod, J. (1972) Pharmacol. Rev. 24, 233-243.

4. Weinshilboum, R., Thoa, N. B., Johnson, D. G., Kopin, I. J., and Axelrod, J. (1971) Science 174, 1349-1351.

5. Weil-Malherbe, H., Axelrod, J., and Tomchick, R. (1959) Science 129, 1226-1227.

6. Merits, I. (1976) Biochem. Pharmacol. 25, 829833.

7. Williams, C. M., Babusico, A. A., and Watson, R. (1960) Amer. J. Physiol. 199, 722-726.

8. Kissinger, P. T., Riggin, R. M., Alcorn, R. L., and Rau, L. D. (1975) Biochem. Med. 13, 299-306.

9. Scratchley, G. A., Masoud, A. M., Stohs, S. J., and Wingard, D. W. (1979) J. Chromatogr. 169, 313-319.

10. Freed, C. R., and Asmus, P. A. (1979) J. Neurochem. 32, 163-168.

11. Hoeldtke, R. D., and Kaufman, S. (1978)Biochem. Pharmacol. 27, 2499-2506.

12. Taylor, K. M., and Laverty, R. (1969) J. Neurochem. 16, 1361-1366.

13. Hoeldtke, R., and Sloan, J. W. (1970) J. Lab. Clin. Med. 75, 159-165.

14. Graefe, K. H., Stefano, F. J. E., and Langer, S. L. (1973) Biochem. Pharmacol. 22, 1147-1160.

15. Bigelow, L. B., Neal, S., and Weil-Malherbe, H. (1971) J. Lab. Clin. Med. 77, 677-683.

16. Shimizu, H., and LaBrosse, E. H. (1969) Biochem. Pharmacol. 18, 1643-1654.

17. Nielsen, M., and Braestrup, C. (1976) J. Neurochem. 27, 1211-1217.

18. Karasawa, T., Furukawa, K., and Shimizu, M. (1978) J. Neurochem. 30, 1525-1530.

19. Muskiet, F. A. J., Fremouw-Ottevangers, D. C., Nagel, G. T., Wolthers, B. G., and deVries, J. A. (1978) Clin. Chem. 24, 2001-2008.

20. Goodall, McC., and Alton, H. (1968) Biochem. Pharmacol. 17, 905-914.

21. Musacchio, J., Kopin, I. J., and Snyder, S. (1964) Life Sci. 3, 769-775.

22. Sjoerdsma, A., and Von Studnitz, W. (1963) Brit. J. Pharmacol. 20, 278-284. 